\section{Implementation of an Urban First-Responder, Semi-Automatic Defibrillation Program Improves Cardiac Arrest Survival}

\author{
Braun O, Clark DM, Valentine WI \\ Center for Prehospital Research and Training, \\ University of California at San Francisco \\ San Francisco, California, USA
}

Hypothesis: Urban first-responder, semi-automatic defibrillation programs increase survival from prehospital cardiac arrest. Methods: Study participants were adult, nontraumatic cardiac arrest victims treated by firefighter first-responders (FFRs) in a busy, single-tier, urban EMS system. Using definitions and data points identical to those recommended by the Utstein Conference, control data were collected prospectively from 16 August 1985 to 28 August 1986. All FFRs then were trained to use and were equipped with semi-automatic defibrillators. Study data were collected prospectively from 1 January 1990 to 31 December 1990 (Group 1) and 1 January 1991 to 31 December 1991 (Group 2). Data were analyzed using the Kendall Tau $t$-test Results: The control group included 620 patients; the two study groups, 469 and 467, respectively. Higher percent survival was noted in Groups 1 and 2 (table). A threefold increase in survival for the most salvageable patient subpopulation (patients who present in VF, are witnessed, and receive bystander CPR [WBCPR VF]) is of low statistical significance due to the small size of this subpopulation.

\begin{tabular}{|c|c|c|c|c|c|c|}
\hline & $\begin{array}{c}\text { Control } \\
{[\% \mathrm{~N}]}\end{array}$ & $\begin{array}{c}\text { Group } 1 \\
{[\% N]}\end{array}$ & $\begin{array}{c}\text { Group } 2 \\
{[\% N]}\end{array}$ & $\begin{array}{c}\% \\
\text { Change }\end{array}$ & tau & p-value \\
\hline Overall & $\begin{array}{r}4.5 \\
{[28 / 620]}\end{array}$ & $\begin{array}{r}4.9 \\
{[23 / 469]}\end{array}$ & $\begin{array}{r}7.3 \\
{[34 / 467]}\end{array}$ & 62 & .04535 & .0581 \\
\hline VF & $\begin{array}{r}9.5 \\
{[19 / 201]}\end{array}$ & $\begin{array}{r}9.2 \\
{[15 / 163]}\end{array}$ & $\begin{array}{r}15.3 \\
{[24 / 157]}\end{array}$ & 61 & .06748 & .1029 \\
\hline $\begin{array}{l}\text { Witnesses } \\
\text { VF }\end{array}$ & $\begin{array}{r}9.4 \\
{[10 / 106]}\end{array}$ & $\begin{array}{r}11.0 \\
{[14 / 127]}\end{array}$ & $\begin{array}{r}16.9 \\
{[21 / 124]}\end{array}$ & 80 & .08739 & .0804 \\
\hline WBCPA VF & $\begin{array}{r}4.5 \\
{[1 / 22]}\end{array}$ & $\begin{array}{r}19.5 \\
{[8 / 41]}\end{array}$ & $\begin{array}{r}20.0 \\
{[8 / 40]}\end{array}$ & 344 & .12474 & 1836 \\
\hline
\end{tabular}

Conclusions: Even in an urban setting with rapid paramedic ALS response, first-responder defibrillation can affect patient survival, most markedly in patients in VF who were witnessed and received bystander CPR.

\section{Effectiveness of Defibrillation by Rural First-Responders and Basic EMTs}

\author{
Garrison HG, * Harning AT, ** Rea NK, ${ }^{+}$Auble TE* \\ * Division of Emergency Medicine, University of Pittsburgh \\ Pittsburgh, Pennsylvania, USA \\ ** EEMCO East, Kersey, Pennsylvania, USA \\ + Erie, Pennsylvania, USA
}

Purpose: Controlled studies have demonstrated the efficacy of defibrillation for sudden death secondary to ventricular!ar fibrillation. The purpose of this on-going study is to determine the effectiveness or practical application-"how well does it work in the real world" - of training rural, first-responders and basic EMTs to defibrillate.

Methods: Design: Retrospective cohort study. Setting. Four contiguous counties in a rural, northwestern region of Pennsylvania. Cohort. All adult, prehospital victims of sudden cardiac death during 1991 and 1992 excluding trauma and drowning victims and 33 patients whose records were incomplete. Cases $(n=113)$ were cardiac arrest patients in service areas in the region in which first-responders and basic EMTs were trained to provide defibrillation with semi-automatic defibrillators. Controls $(\mathrm{n}=76)$ were cardiac arrest victims in service areas with no defibrillating first-responders or basic EMTs.

Results: There were no significant differences between cases and controls in mean age (66 years vs 68 years), gender (male $67 \%$ vs $62 \%)$, bystander- (42\% vs $50 \%$ ) or provider-witnessed arrests (8\% vs $11 \%$ ), or bystander CPR ( $34 \%$ vs $41 \%$ ). Significantly less cases ( $74 \%$ vs $96 \%, p=.0027$ ) received paramedic advanced life support. Of the 113 cases, $36(32 \%)$ were defibrillated by first-responders or basic EMTs, and seven (6.2\%) were discharged from the hospital alive. Of the 76 controls, one $(1.3 \%)$ was discharged from the hospital alive. The difference between cases and controls in numbers of patients discharged alive was not significant $(p=.146 ; 80 \%$ power to detect a difference of $8 \%$ ). Of 36 cases with a "shockable" rhythm defibrillated by a first-responder or basic EMT, seven or $19.4 \%$ were discharged alive.

Conclusion: These "real world" results suggest that training rural first-responders and basic EMTs to defibrillate may not improve the overall survival-to-discharge rate for victims of sudden death. However, in patients with "shockable" rhythms, the results, thus far, compare favorably with defibrillation efficacy studies. This suggests that defibrillation by rural first-responders and basic EMTs may be an effective strategy. 